\title{
ArtiFacts: Corporal Robert O. Burkhardt's Right Leg
}

\author{
Alan J. Hawk BA
}

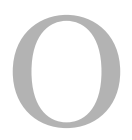

n April 19, 1945, Allied tanks traveling down a German road in preparation for the next day's assault were attacked by a German ground-attack aircraft. Corporal (Cpl.) Robert O. Burkhardt of the 4th Infantry Division sustained a traumatic amputation of his right arm, an

A note from the Editor-in-Chief:

We are pleased to present to our readers the next installment of ArtiFacts. In each column, the Collections Manager of the Historical Collections Division of the National Museum of Health and Medicine will present a photograph of a visually or historically interesting artifact from the museum's collection, and provide the story behind the picture. Now a National Historic Landmark, the NMHM was originally developed from the Army Medical Museum, which was established during the Civil War to collect "specimens of morbid anatomy together with projectiles and foreign bodies removed." Its mission today is to inspire interest in and promote the understanding of medicine past, present, and future - to the public.

The author certifies that neither he, nor any members of his immediate family, have any commercial associations (such as consultancies, stock ownership, equity interest, patent/licensing arrangements, etc) that might pose a conflict of interest in connection with the submitted article. All ICMJE Conflict of Interest Forms for authors and Clinical Orthopaedics and Related Research ${ }^{\mathbb{B}}$ editors and board members are on file with the publication and can be viewed on request. open fracture of the middle-third of his right femur, as well as penetrating wounds to his left knee, right back, and neck. The battalion surgeon did not think Cpl. Burkhardt would survive and refused to give him plasma, relenting only when an orderly from Cpl. Burkhardt's unit offered a direct transfusion of his own blood.

But Cpl. Burkhardt survived, and was evacuated to a hospital in the United Kingdom where physicians treated his wounds and placed his leg in traction. Although he sustained extensive nerve damage, and vascular injury impaired the circulation in his right leg, Cpl. Burkhardt refused amputation. Five physicians evaluated the injured leg, but only one believed he could save it. Doctors informed Cpl.

The opinions expressed are those of the writers, and do not reflect the opinion or policy of $C O R R^{\circledR}$ or The Association of Bone and Joint Surgeons ${ }^{\circledR}$.

The opinions or assertions herein are those of the author and do not represent the views of the Department of the Army, Navy or Air Force or of the Department of Defense.

A. J. Hawk BA ( $\square)$

National Museum of Health and

Medicine, Defense Health Agency, 2460

Linden La., Silver Spring, MD 20910,

USA

e-mail: alan.j.hawk.civ@mail.mil
Burkhardt that it would be a miracle if his leg lasted a decade.

In order to improve circulation and control infections, the doctor lowered Cpl. Burkhardt's leg and elevated his head. The leg developed edema, which had to be controlled by elevation. Cpl. Burkhardt later wrote, "I thought I was a yo-yo," as the medical staff balanced circulation and edema by raising and lowering his leg [3].

Upon his return to the United States, Cpl. Burkhardt was transferred to Walter Reed General Hospital. Just before he was due to go on leave from Walter Reed in November 1945, an overzealous physical therapist fractured Cpl. Burkhardt's leg during therapy, resulting in another surgical procedure. Surgeons implanted a plate and a graft, but a femoral malunion resulted, and Cpl. Burkhardt walked with a $35^{\circ}$ internal rotation deformity [4].

A physician fitted Cpl. Burkhardt with a knee-ankle-foot orthosis (Fig. 1) in order to keep weight off of the fracture and correct the internal rotation deformity [1]. The orthosis did not permit articulation of the knee, which caused an awkward peg-leg gait that was exhausting and painful [5]. Cpl. Burkhardt's leg would swell from edema during his 28-day leave period, 


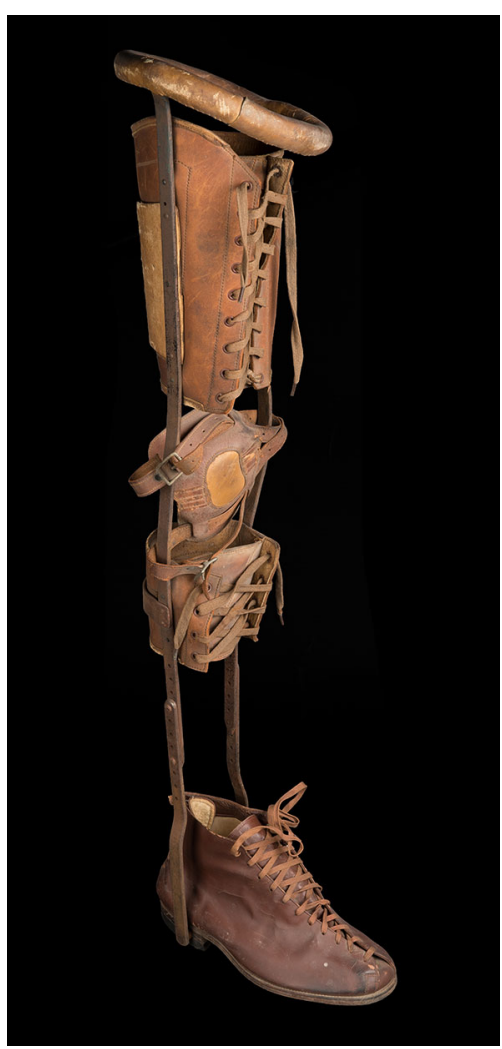

Fig. 1 A knee-ankle-foot orthosis worn by Cpl. Robert O. Burkhardt, wounded-inaction in Germany during World War II is shown. This brace immobilized Cpl. Burkhardt's severely damaged right leg, kept weight off of the fracture, and straightened his foot. Disclosure: This image has been manipulated using dodging and burning techniques. It has been cropped to emphasize the subject. (National Museum of Health and Medicine photo illustration by Matthew Breitbart). forcing him to remove the brace. Though he rarely left his apartment, the brace allowed him to walk, and the fracture eventually healed. After his brace was modified to accommodate for the swelling, Cpl. Burkhardt showed enough progress to receive another furlough. He was discharged 2 years to the day of his injury [3].

In a sense, Cpl. Burkhardt's outcome was ordinary-only a small percentage of soldiers underwent amputation during World War II (1290 of 39,600 patients sustaining extremity trauma treated at hospitals in the European Theater of Operations between August 1944 and February 1945 [2]). But the journey to that outcome was far from ordinary. Fearing he would be unable to provide for his family as a double amputee, Cpl. Burkhardt went against medical advice and refused amputation multiple times-a decision that saved his leg, but at a considerable cost. Poor circulation resulted in edema, with several episodes resulting in hospitalization. Limited mobility prevented him from completing an occupational training program, and because he had both legs, Burkhardt (now a civilian) was found ineligible for certain veterans programs. The only job he could perform was as a tool room clerk. When worked slowed, Burkhardt elevated his leg on a stool.

For all those challenges, Burkhardt could say he lived a full life, held a job, and provided for his family. The military doctors believed it would be a miracle if his right leg lasted a decade; it served him more than 50 years.

\section{References}

1. Carlisle H. Splinting war fractures. In Jones R, ed. Orthopedic Surgery of Injuries. London, England: Henry Frowde; 1922:91-130.

2. Cleveland M. Orthopedic surgery in the European theater of operations. A brief resume. Ann Surg. 1946;124:188-200.

3. Veterans Administration. Accession Record 2010.0007. Statement in support of claim, Burkhardt, Robert Oscar, claim $13 \quad 010 \quad 614$ (dated November 28, 1973). National Museum of Health and Medicine, Silver Spring MD.

4. Veterans Administration Board of Veterans Appeals. Accession Record 2010.0007. Ruling M-15274, Burkhardt, Robert O. (dated July 22, 1947). National Museum of Health and Medicine, Silver Spring, MD.

5. Yakimovich T. Engineering design review of stance-control knee-anklefoot orthoses. Journal of Rehabilitation Research and Development 46.2 (2009):256-67. 